\title{
Optogenetic Inhibition Reveals Distinct Roles for Basolateral Amygdala Activity at Discrete Time Points during Risky Decision Making
}

\author{
Caitlin A. Orsini, ${ }^{1}$ Caesar M. Hernandez, ${ }^{2}$ Sarthak Singhal, ${ }^{3}{ }^{-}$Kyle B. Kelly, ${ }^{3}$ Charles J. Frazier, ${ }^{3}$ Jennifer L. Bizon, ${ }^{1,2,4}$ \\ and Barry Setlow ${ }^{1,2,4,5}$ \\ ${ }^{1}$ Department of Psychiatry, ${ }^{2}$ Department of Neuroscience, ${ }^{3}$ Department of Pharmacodynamics, ${ }^{4}$ Center for Addiction Research and Education, and \\ ${ }^{5}$ Department of Psychology, University of Florida, Gainesville, Florida 32610
}

\begin{abstract}
Decision making is a multifaceted process, consisting of several distinct phases that likely require different cognitive operations. Previous work showed that the basolateral amygdala (BLA) is a critical substrate for decision making involving risk of punishment; however, it is unclear how the BLA is recruited at different stages of the decision process. To this end, the current study used optogenetics to inhibit the BLA during specific task phases in a model of risky decision making (risky decision-making task) in which rats choose between a small, "safe" reward and a large reward accompanied by varying probabilities of footshock punishment. Male Long-Evans rats received intra-BLA microinjections of viral vectors carrying either halorhodopsin (eNpHR3.0-mCherry) or mCherry alone (control) followed by optic fiber implants and were trained in the risky decision-making task. Laser delivery during the task occurred during intertrial interval, deliberation, or reward outcome phases, the latter of which was further divided into the three possible outcomes (small, safe; large, unpunished; large, punished). Inhibition of the BLA selectively during the deliberation phase decreased choice of the large, risky outcome (decreased risky choice). In contrast, BLA inhibition selectively during delivery of the large, punished outcome increased risky choice. Inhibition had no effect during the other phases, nor did laser delivery affect performance in control rats. Collectively, these data indicate that the BLA can either inhibit or promote choice of risky options, depending on the phase of the decision process in which it is active.
\end{abstract}

Key words: basolateral amygdala; choice; decision making; optogenetics; punishment; risk

Significance Statement

To date, most behavioral neuroscience research on neural mechanisms of decision making has used techniques that preclude assessment of distinct phases of the decision process. Here we show that optogenetic inhibition of the BLA has opposite effects on choice behavior in a rat model of risky decision making, depending on the phase in which inhibition occurs. BLA inhibition during a period of deliberation between small, safe and large, risky outcomes decreased risky choice. In contrast, BLA inhibition during receipt of the large, punished outcome increased risky choice. These findings highlight the importance of temporally targeted approaches to understand neural substrates underlying complex cognitive processes. More importantly, they reveal novel information about dynamic BLA modulation of risky choice.

\section{Introduction}

The ability to make adaptive choices requires multiple cognitive operations that work in concert to guide efficient and optimal behavior (Rangel et al., 2008). For example, an organism must

\footnotetext{
Received Aug. 17, 2017; revised Oct. 1, 2017; accepted 0ct. 13, 2017.

Author contributions: C.A.O., C.M.H., C.J.F., J.L.B., and B.S. designed research; C.A.O., C.M.H., S.S., and K.B.K. performed research; C.J.F. contributed unpublished reagents/analytic tools; C.A.O., C.M.H., S.S., K.B.K., C.J.F., J.L.B., and B.S. analyzed data; C.A.O., S.S., C.J.F., J.L.B., and B.S. wrote the paper.

This work was supported by the McKnight Brain Research Foundation, Thomas H. Maren Fellowship, and NIH K99DA041493 to C.A.O., McKnight Predoctoral Fellowship, the Pat Tillman Foundation to C.M.H., and NIH R01DA036534 to B.S.

The authors declare no competing financial interests.
}

calculate the objective and subjective value of the available options, which entails evaluating the relative value of both the benefits and costs associated with each option. This information must be acquired from past experience, such as the contingencies of previous actions and their outcomes, as well as other motivational (e.g., hunger) and environmental (e.g., presence of salient predictive cues) factors. Finally, the organism must determine

Correspondence should be addressed to either of the following: Dr. Caitlin A. Orsini or Dr. Barry Setlow, Department of Psychiatry, University of Florida College of Medicine, PO Box 100256, Gainesville, FL 32610-0256, E-mail: orsini@ufl.edu or setlow@ufl.edu.

DOI:10.1523/JNEUROSCI.2344-17.2017

Copyright $\odot 2017$ the authors $\quad 0270-6474 / 17 / 3711537-12 \$ 15.00 / 0$ 
the value of the actual outcome of its choice, and use this information as feedback to guide future choices. Together, these processes allow an organism to execute its choice behavior as appropriate to its past, current, and anticipated future conditions. While the majority of individuals are able to effectively engage these processes and make adaptive decisions, individuals with psychiatric diseases, such as substance use disorder, anorexia nervosa, and post-traumatic stress disorder, exhibit impaired decision making (Bechara and Damasio, 2002; Crowley et al., 2010; Najavits et al., 2011; Schneider et al., 2012; Kaye et al., 2013; Gonzalez et al., 2015; Dekkers et al., 2016), often resulting in maladaptive choices. The specific components of the decisionmaking process that are perturbed in these pathological conditions, however, are unclear.

Decision making is mediated by interconnected brain structures within the mesocorticolimbic circuit (Orsini et al., 2015b). One such structure within this circuit that has received considerable attention in cost/benefit decision making is the BLA (Winstanley and Floresco, 2016). Using well-validated rodent models of risk-based decision making, previous work has shown that lesions or pharmacological inactivation of the BLA result in disadvantageous choices (Winstanley et al., 2004; Ghods-Sharifi et al., 2009; Zeeb and Winstanley, 2011; Hosking et al., 2014; Tremblay et al., 2014). This is consistent with neuroimaging data showing that the amygdala is activated during assessment of risky choices (De Martino et al., 2006; Roiser et al., 2009) and is hypoactive in individuals with impaired risky decision making (Crowley et al., 2010; Gowin et al., 2013). More recently, the BLA has been implicated in decision making involving risk of explicit punishment (Orsini et al., 2015a). In well-trained rats, BLA lesions increased choice of a large reward associated with risk of footshock punishment. These data suggested that the BLA is critical for the integration of reward- and punishment-related information to guide optimal behavior. Importantly, however, it is unclear how and at what point in the decision-making process this integration occurs.

In vivo electrophysiological studies show that BLA neurons do not respond uniformly to salient stimuli but instead mediate different aspects of motivated behavior. For example, different populations of BLA neurons respond differentially to rewarding and aversive outcomes (Schoenbaum et al., 1998, 1999; Paton et al., 2006; Belova et al., 2007, 2008; Shabel and Janak, 2009; Sangha et al., 2013; Gore et al., 2015). These neuronal populations are organized into distinct circuits within the BLA (Zhang et al., 2013) and appear to have distinct projection targets (Namburi et al., 2015; Beyeler et al., 2016). In addition, different populations of amygdala neurons can encode distinct components of future plans to obtain a goal, such as the subjective value of the plan itself or the number of steps required to obtain the goal (Hernádi et al., 2015). This functional heterogeneity within the BLA supports the hypothesis that this structure is differentially engaged during decision making involving rewarding and aversive outcomes. How the BLA is recruited, however, may depend on the specific cognitive components of the decision-making process. In other words, how the BLA contributes to the deliberative process of decision making may be distinct from how it contributes to processing the outcomes of past choices.

The advent of optogenetics affords the ability to test this hypothesis by examining BLA involvement in decision making during distinct components of the decision process. Hence, the experiments herein examined the effects of BLA inhibition during the deliberation and outcome phases of a risky decisionmaking task involving risk of explicit punishment.

\section{Materials and Methods}

\section{Subjects}

Male Long-Evans rats (weighing 250-275 g upon arrival; Charles River Laboratories) were individually housed and kept on a $12 \mathrm{~h}$ light/dark cycle with free access to food and water, except as indicated below. Upon arrival, rats were handled daily for 1 week before undergoing surgery. During behavioral testing, rats were maintained at $90 \%$ of their freefeeding weight, with their target weights adjusted upward by $5 \mathrm{~g} /$ week to account for growth. Animal procedures were conducted in accordance with the University of Florida Institutional Animal Care and Use Committee and followed guidelines of the National Institutes of Health.

\section{Apparatus}

Behavioral testing was conducted in three computer-controlled operant test chambers (Coulbourn Instruments), each of which was contained in a sound-attenuating cabinet. Chambers were equipped with a centrally located food trough (TAMIC Instruments), which projected $3 \mathrm{~cm}$ into the chamber and contained a photobeam to detect trough entries. The trough was connected to a feeder, from which $45 \mathrm{mg}$ food pellets (Test Diet, AIN-76A, 5TUL) were delivered into the trough. A nosepoke hole was located above the food trough, and two retractable levers were positioned to the left and right of the trough, $11 \mathrm{~cm}$ above the floor of the chamber. A 1.12 W lamp was positioned on the back wall of the soundattenuating cabinet and served as a house light. The floor of the test chamber was comprised of stainless-steel rods connected to a shock generator that delivered scrambled footshocks. Each operant test chamber was interfaced with a computer running Graphic State 4.0 software (Coulbourn Instruments), which controlled chamber hardware (e.g., lever insertion, nosepoke illumination, food pellet delivery) and recorded task events.

\section{Laser delivery}

During behavioral test sessions, laser light $(560 \mathrm{~nm}, 8-10 \mathrm{~mW}$ output, Shanghai Laser \& Optics Century) was delivered bilaterally into the BLA in rats expressing halorhodopsin (eNpHR3.0 group) or mCherry (control group) in the BLA. To reach the brain, light was passed from the laser through a patch cord $(200 \mu \mathrm{m}$ core, Thor Labs), a rotary joint $(1 \times 2,200$ $\mu \mathrm{m}$ core, Doric Lenses) located above the operant chamber, 2 additional patch cords ( $200 \mu \mathrm{m}$ core, $0.22 \mathrm{NA}$, Thor Labs), and bilateral optic fibers (200 $\mu \mathrm{m}$ core, $0.22 \mathrm{NA}, 8.3 \mathrm{~mm}$ in length; Precision Fiber Products) implanted in the BLA. The laser was interfaced with the computer running Graphic State 4.0 software to allow for precise timing of light delivery during different task phases.

\section{Surgical procedures}

Rats were anesthetized with isoflurane gas $\left(1 \%-5 \%\right.$ in $\left.\mathrm{O}_{2}\right)$ and received subcutaneous injections of meloxicam $(2 \mathrm{mg} / \mathrm{kg})$, buprenorphine $(0.05$ $\mathrm{mg} / \mathrm{kg}$ ), and sterile saline $(10 \mathrm{ml})$. Rats were placed into a stereotaxic apparatus (David Kopf Instruments), and the scalp was cleaned with a chlorohexidine/isopropyl alcohol swab. A sterile adhesive surgical drape was subsequently placed over the body.

For rats used in in vitro electrophysiology experiments, the scalp was incised and retracted, and the skull was leveled to ensure that bregma and lambda were in the same horizontal plane. Two burr holes were drilled for bilateral virus injections into the BLA (anteroposterior: -3.2 , mediolateral: \pm 4.9 , dorsoventral: $-8.5,-8.1 \mathrm{~mm}$ from skull surface). At each site, an injection needle was lowered to the target depth and AAV5CaMKII $\alpha$-eNpHR3.0-mCherry (University of North Carolina Vector Core) was infused into the BLA $(0.4 \mu \mathrm{l}$ at the ventral DV coordinate and $0.2 \mu \mathrm{l}$ at the dorsal DV coordinate, at a rate of $0.5 \mu \mathrm{l} / \mathrm{min}$ ). The injection needle was attached to polyethylene tubing, which was connected to a $10 \mu \mathrm{l}$ Hamilton syringe mounted on a syringe pump (Harvard Apparatus). After each injection, the needle was left in place for an additional 5 min to allow for diffusion of the virus. The incision was then sutured, and rats were given an additional $10 \mathrm{ml}$ of saline before being placed on a heating pad to recover from surgery.

For rats used in behavioral experiments, the scalp was incised and retracted, and six small burr holes were drilled into the skull for placement of jeweler's screws: two screws were placed anterior to bregma, two 
A

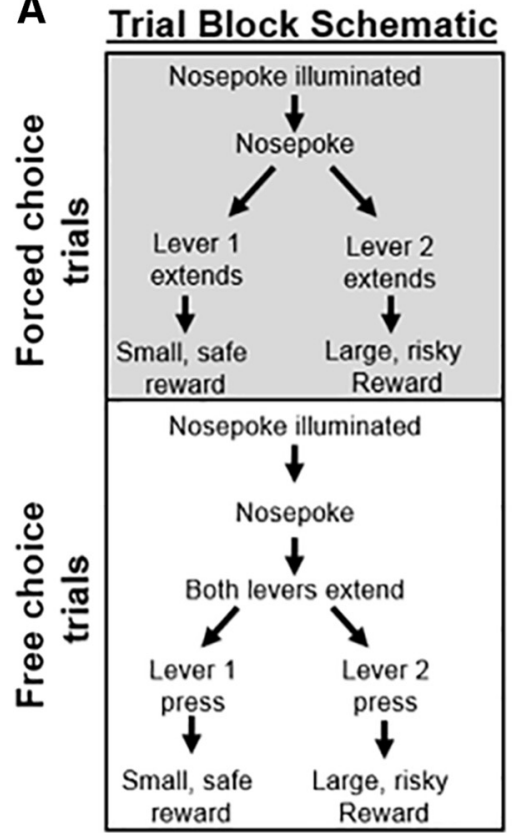

B

Individual Trial Design

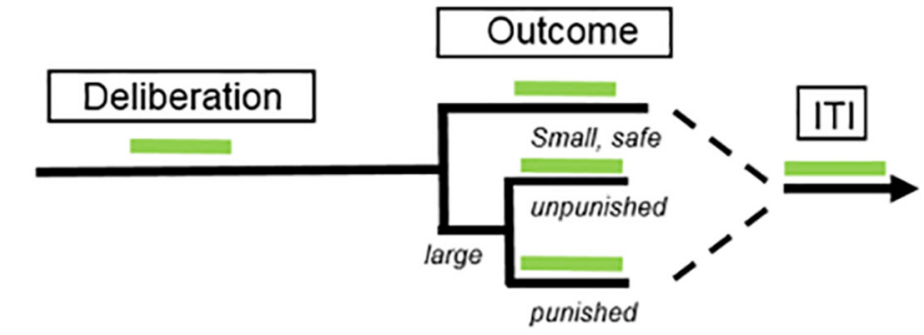

Figure 1. Design of the RDT.A, Each block consists of 8 forced choice trials and 20 free choice trials. Each free choice trial consists of a deliberation and outcome phase. Rats must nosepoke for the extension of either one lever (forced choice trial) or both levers (free choice trial). A press on one lever yields a small safe reward, and a press on the other yields a large reward accompanied by variable probabilities of footshock punishment. $\boldsymbol{B}$, Laser delivery occurred at 1 of 5 possible phases during each free choice trial (with laser delivery during each test session taking place in only 1 of the 5 phases). Green bars represent periods of laser delivery.

between bregma and lambda, and two posterior to lambda. This configuration was used to ensure that the headcap was secured evenly across the skull surface. After leveling the skull to ensure that bregma and lambda were in the same horizontal plane, two additional burr holes were drilled for bilateral implantation of guide cannulae (22 gauge; Plastics One) above the BLA (anteroposterior: -3.3 , mediolateral: \pm 4.9 , dorsoventral: -7.3 from skull surface). Dental cement was used to anchor the cannulae in place. Once the dental cement was set, an injection needle was lowered into each cannula (the tip of the needle extended $1.5 \mathrm{~mm}$ beyond the end of the cannula), and AAV5-CaMKII $\alpha$-eNpHR3.0-mCherry or AAV5CaMKII $\alpha$-mCherry (University of North Carolina Vector Core) was infused into the BLA $(0.6 \mu \mathrm{l}$ at a rate of $0.5 \mu \mathrm{l} / \mathrm{min})$. A sterile stylet was inserted into each cannula at the completion of the injections. Rats were given an additional $10 \mathrm{ml}$ of saline and were placed on a heating pad to recover from surgery. Rats were allowed to recover for 1 week before being food restricted in preparation for behavioral testing.

In vitro electrophysiology

Rats $(n=4)$ were anesthetized with an intraperitoneal injection of a $75-100 \mathrm{mg} / \mathrm{kg}$ ketamine and $5-10 \mathrm{mg} / \mathrm{kg}$ xylazine solution and were decapitated using a small animal guillotine. Their brains were rapidly extracted and coronal sections containing the BLA (300 $\mu$ m thick) were obtained using a Leica VT 1000s vibratome while submerged in ice-cold sucrose-laden oxygenated aCSF containing the following (in $\mathrm{mM}$ ): $2 \mathrm{KCl}$, $1.25 \mathrm{NaH}_{2} \mathrm{PO}_{4}, 1 \mathrm{MgSO}_{4}, 10 \mathrm{D}$-glucose, $1 \mathrm{CaCl}_{2}, 206$ sucrose, and 25 $\mathrm{NaHCO}_{3}$. Slices were then incubated for $30 \mathrm{~min}$ at $37^{\circ} \mathrm{C}$ in aCSF, which contained the following (in mM): $124 \mathrm{NaCl}, 2.5 \mathrm{KCl}, 1.23 \mathrm{NaH}_{2} \mathrm{PO}_{4}, 3$ $\mathrm{MgSO}_{4}, 10 \mathrm{D}$-glucose, $1 \mathrm{CaCl}_{2}$, and $25 \mathrm{NaHCO}_{3}$. Following this incubation period, slices were allowed to equilibrate to room temperature for a minimum of $30 \mathrm{~min}$ before being used for experiments. All solutions were saturated with $95 \% \mathrm{O}_{2} / 5 \% \mathrm{CO}_{2}$ to maintain a $\mathrm{pH}$ of 7.3 . For wholecell patch-clamp recordings, slices were transferred to a slice chamber where they were continuously perfused at a rate of $1.5-2 \mathrm{ml} / \mathrm{min}$ with an aCSF bath solution that contained the following (in $\mathrm{mM}$ ): $126 \mathrm{NaCl}, 3$ $\mathrm{KCl}, 1.2 \mathrm{NaH}_{2} \mathrm{PO}_{4}, 1.5 \mathrm{MgSO}_{4}, 11 \mathrm{D}$-glucose, $2.4 \mathrm{CaCl}_{2}$, and $25 \mathrm{NaHCO}_{3}$. This solution was also saturated with $95 \% \mathrm{O}_{2} / 5 \% \mathrm{CO}_{2}$ to maintain a $\mathrm{pH}$ of 7.3 , and bath temperature was maintained at $30^{\circ} \mathrm{C}-32^{\circ} \mathrm{C}$. Slices were visualized using infrared differential interference contrast microscopy with an Olympus BX51WI upright stereomicroscope, a 12-bit IRC CCD camera (QICAM Fast 1394, QImaging), and a $40 \times$ water-immersion objective. Patch pipettes were prepared with a Flaming/Brown type pipette puller (Sutter Instrument, P-97) from $1.5 \mathrm{~mm} / 0.8 \mathrm{~mm}$ borosilicate glass capillaries (Sutter Instrument) and pulled to a tip resistance of 4-7 $\mathrm{M} \Omega$. Whole-cell patch-clamp recordings were performed using an Axon Mutliclamp 700B amplifier (Molecular Devices), and data were collected at $20 \mathrm{kHz}$, filtered at $2 \mathrm{kHz}$, and recorded with a Digidata $1322 \mathrm{~A}$ using Clampex version 9 or 10 (Molecular Devices). BLA neurons expressing mCherry were identified using an epifluorescence microscopy (XF102-2 filter set, Omega Optical, excitation: 540-580 nm, emission: 615-695 $\mathrm{nm})$. The light source for epifluorescence microscopy was an X-Cite Series 120Q (Lumen Dynamics). Whole-cell patch-clamp recordings were initiated under infrared differential interference contrast using a potassium-based internal solution that contained the following (in $\mathrm{mM}$ ): 130 K-gluconate, $10 \mathrm{KCl}, 5 \mathrm{NaCl}, 2 \mathrm{MgCl}_{2}, 0.1$ EGTA, $2 \mathrm{Na}_{2}$-ATP, 0.3 NaGTP, 10 HEPES, and 10 phosphocreatine, $\mathrm{pH}$ adjusted to 7.3 using $\mathrm{KOH}$ and volume adjusted to $285-300 \mathrm{mOsm}$. Halorhodopsin was activated using $1000 \mathrm{~ms}$ light pulses, delivered through the excitation filter in the XF102-2 filter set. Experiments were performed in voltage clamp (at $-70 \mathrm{mV}$ ), in current clamp (at $\mathrm{I}=0$ ), or in current clamp during $100-$ $200 \mathrm{pA}$ current injection that was sufficient to drive action potentials. Data were analyzed using custom software written in OriginC (OriginLab, Northampton, MA) by C.J.F.

\section{Behavioral procedures}

Risky decision-making task (RDT). Rats were initially shaped to perform the various components of the decision-making task (e.g., lever pressing; nosepoking to initiate a trial) as described previously (Orsini et al., 2015a). They then began training in the RDT, which was comprised of three 28-trial blocks and lasted $56 \mathrm{~min}$ in duration (this task design was a modification of a similar design used in our laboratory) (Simon et al., 2009; Orsini et al., 2015a). Each 40 s trial (Fig. 1A) began with illumination of the nosepoke and house light. Upon nosepoking, the nosepoke light was extinguished and either a single lever (forced choice trials) or both levers (free choice trials) extended into the chamber. If rats failed to nosepoke within $10 \mathrm{~s}$, the trial was considered an omission. A press on one lever (left or right; counterbalanced across rats) always yielded a 
small, "safe" food reward (one food pellet), and a press on the other lever always yielded a large, "risky" food reward ( 2 food pellets). Delivery of the large reward was accompanied by a variable probability of punishment in the form of a mild footshock $(0.25-0.6 \mathrm{~mA})$. The probability of punishment was contingent on a preset probability specific to each block of trials: the probability in the first block was set to $0 \%$ and increased across successive blocks (25\%, 75\%, respectively). The large food reward was delivered regardless of punishment delivery. Although the levers were counterbalanced across rats, the identities of the small, "safe" lever and large, "risky" lever remained constant for each rat throughout testing. Each block of trials started with eight forced choice trials in which a single lever was extended into the chamber. It is through these forced choice trials that the punishment contingencies for that block were established (four presentations of each lever, randomly presented). During forced choice trials, the probability of punishment following a press for the large reward was dependent upon the outcomes of the other forced choice trial lever presses in that block. For example, in the $25 \%$ block, one and only one of the four forced choice trials (randomly selected) resulted in footshock. Similarly, in the $75 \%$ block, three and only three of the forced choice trials resulted in footshock. The forced choice trials in each block were followed by 20 free choice trials in which both levers were extended. If rats failed to lever press within $10 \mathrm{~s}$, the house light was extinguished and the trial was counted as an omission. In contrast to the forced choice trials, the probability of punishment in free choice trials was independent, such that the shock probability on each trial was the same regardless of shock delivery on previous trials in that block. During RDT training, shock intensities were adjusted individually for each rat to ensure that there was sufficient parametric space to observe either increases or decreases in risk taking during optogenetic inhibition of BLA.

Upon reaching stable baseline performance (for description of stability, see Experimental design and statistical analysis), rats were lightly anesthetized and optic fibers were inserted into the BLA cannulae such that they extended $1 \mathrm{~mm}$ beyond the tips of the cannulae. The fibers were cemented into position, and dust caps were placed on the fibers to keep them free from debris. In each subsequent RDT session, spring-insulated patch cords fastened to the rotary joint were attached to the implanted fibers in the rat. Rats were trained in this manner until their performance returned to baseline levels ( $\sim 3$ sessions). Upon reaching this criterion, optogenetic manipulations during test sessions began (note that shock intensities were not adjusted between baseline and laser delivery sessions). Laser delivery occurred only on free choice trials, during three different phases (Fig. 1B): (1) deliberation, (2) reward outcome, and (3) intertrial interval (ITI). The deliberation phase consisted of the time between the nosepoke to trigger lever extension and a lever press, and thus captured the period in which rats were presumably deciding between the two available options. Laser delivery commenced $0.5 \mathrm{~s}$ before nosepoke illumination and remained on until a lever press occurred or $5 \mathrm{~s}$ elapsed, whichever occurred first. For the reward outcome phase, there were three different laser delivery conditions: (1) delivery of the small safe reward, (2) delivery of the large reward without punishment, and (3) delivery of the large reward with punishment. During each outcome condition, laser delivery began as soon as the rat pressed the lever to yield that outcome and lasted for $5 \mathrm{~s}$. Finally, during the ITI phase, laser delivery (5 s) occurred 8-15 s after each reward delivery. A randomized, within-subjects design was used such that each rat was tested across multiple laser delivery phases. Because of attrition due to loss of headcaps, however, not all rats were tested for all phases. In between each laser delivery session, rats were tethered and tested in the RDT until their performance in the task across two consecutive sessions was no different from their original baseline before any laser delivery. If choice performance shifted during these rebaselining sessions, shock intensities were adjusted until performance was comparable with the original baseline.

Determination of shock intensity threshold. Upon completion of testing in the RDT, rats in the eNpHR3.0 group underwent test sessions in which their shock reactivity was assessed under laser and no laser delivery conditions. The procedures were based on those developed by Bonnet and Peterson (1975) to determine the shock thresholds at which specific motor responses were elicited. These test sessions occurred across $2 \mathrm{~d}$, with each day consisting of two tests: one with laser delivery and the other without. The order of the test sessions on each day was counterbalanced across the $2 \mathrm{~d}$. Regardless of laser delivery condition, each test session began with a 2 min baseline period followed by delivery of an unsignaled footshock $(0.4 \mathrm{~mA}, 1 \mathrm{~s})$, which decreased spontaneous motor activity and facilitated detection of motor responses at subsequent low shock intensities. The shock intensity was then set to $0.05 \mathrm{~mA}$, and a series of five footshocks ( $1 \mathrm{~s}$ each), each separated by $10 \mathrm{~s}$, was delivered. After each series of footshocks, the shock intensity was increased by $0.025 \mathrm{~mA}$. The increase in shock intensities continued until all motor responses of interest were observed. The shock intensity threshold for a given motor response was determined by the shock intensity at which the given response was elicited by 3 of the 5 footshocks in a series. The motor responses for which shock thresholds were determined consisted of (1) flinch of a paw or a startle response, (2) elevation of one or two paws, or (3) rapid movement of three or all paws. For test sessions in which the laser was on, light was delivered bilaterally $(560 \mathrm{~nm}, 8-10 \mathrm{~mW})$ using the same procedures and system used during decision-making sessions. To mimic parameters used for laser delivery during the large, punished outcome, laser delivery and footshock were delivered concomitantly, but the laser remained on for an additional $4 \mathrm{~s}$ (total laser on time of $5 \mathrm{~s}$ ). Even though no light was delivered during test sessions without laser delivery, rats were still tethered for the duration of the test.

\section{Histology and immunohistochemistry}

Upon completion of behavioral testing, rats were overdosed with Euthasol and transcardially perfused with cold $0.1 \mathrm{~m}$ PBS followed by cold $4 \%$ PFA. Brains were extracted and postfixed in $4 \%$ PFA for $24 \mathrm{~h}$ before being transferred into a $20 \%$ sucrose in $0.1 \mathrm{M}$ PBS solution. Brains were sectioned on a cryostat $(35 \mu \mathrm{m})$ maintained at $-20^{\circ} \mathrm{C}$. Coronal sections $(30 \mu \mathrm{m})$ were collected in a 1 -in- 4 series and placed in wells filled with $0.1 \mathrm{M}$ PBS.

Immunohistochemistry was performed on free-floating tissue sections and began with three $10 \mathrm{~min}$ washes in $0.1 \mathrm{M}$ TBS. Tissue was then incubated in 3\% normal donkey serum and $0.3 \%$ Triton X-100 in $0.1 \mathrm{M}$ TBS for $1 \mathrm{~h}$ at room temperature. Tissue was then immediately transferred into primary antibody (rabbit anti-mCherry at 1:1000, ab167453, Abcam solution in 3\% normal donkey serum and $0.3 \%$ Triton X-100) for $72 \mathrm{~h}$ at $4^{\circ} \mathrm{C}$. After primary antibody incubation, tissue was washed three times in $0.1 \mathrm{M}$ TBS for $10 \mathrm{~min}$ and then incubated in secondary antibody solution (donkey anti-rabbit conjugated to AlexaFluor-488 at 1:300, A-21206, Invitrogen in 3\% normal donkey serum and $0.3 \%$ Triton $\mathrm{X}-100$ ) for $2 \mathrm{~h}$ at room temperature. Finally, tissue was washed three times in $0.1 \mathrm{M}$ TBS for $10 \mathrm{~min}$ and then mounted onto electrostatic slides (Fisherbrand) in 0.1 м TBS. Slides were coverslipped with Prolong Gold Antifade Mountant (P36941, Invitrogen) and sealed with clear nail polish.

\section{Experimental design and statistical analyses}

Using pilot data collected from several eNpHR3.0 rats, a power analysis was conducted with $G^{\star}$ Power software. This analysis indicated that a sample size of at least 4 rats was required to detect significant differences between baseline and laser delivery conditions with effect sizes of $\geq 0.8$, assuming an $\alpha$ level of 0.05 . To account for possible attrition over the course of the experiment, group sizes were larger than that calculated from the power analysis. A total of 35 male Long-Evans rats were used in these experiments. Twenty-six rats received intra-BLA microinjections of the viral vector containing eNpHR3.0, 4 of which were used for in vitro electrophysiology experiments. Nine rats received intra-BLA microinjections of the viral vector containing mCherry. Within the eNpHR3.0 group, some rats did not undergo every laser delivery session due to illness or loss of headcaps over the course of the experiment. In addition, only a subset of rats $(n=6)$ was used for shock threshold testing. In the control group, there was attrition due to illness or loss of headcaps, resulting in only 4 of the initial nine rats completing the laser delivery sessions. All 4 rats, however, completed all laser delivery conditions.

Raw data files were analyzed using a custom analysis template written in Graphic State 4.0 software. This template extracted data for specific task events of interest: numbers of lever presses during forced and free choice trials, latencies to press levers, latencies to nosepoke, and numbers 
of omissions during forced and free choice trials. The data analysis procedures were conducted identically for the eNpHR3.0 and control groups. Choice performance in each block of the RDT was measured as the percentage of free choice trials (each block consisted of 20 free choice trials; excluding omissions) on which rats chose the large, risky outcome. Each rat was trained in the RDT until it reached stable baseline performance. Stable baseline was obtained when the coefficient of variation for choice of the large, risky outcome was $<20 \%$ in each block for at least two consecutive sessions. Once this criterion was met, laser delivery sessions commenced. In between each laser delivery session, rats were retrained in the RDT until their behavior restabilized, which was determined using the same criterion. To ensure that the baseline after laser delivery was similar to the original baseline (before any laser delivery sessions took place), the coefficient of variation of the means of each block between baseline sessions had to fall $<20 \%$. Upon reaching this criterion, rats were advanced to the next laser delivery session. Effects of laser delivery (i.e., BLA inhibition) on choice performance were determined using a two-factor repeated-measures ANOVA with session (i.e., baseline vs inhibition) and trial block as within-subjects factors. In all analyses, a $p$ value of $\leq 0.05$ was considered statistically significant. Latencies to nosepoke to trigger lever extension were measured as the interval between the illumination of the nosepoke light and a nosepoke response, excluding trials on which the rat failed to nosepoke altogether (omissions). Using a repeated-measures ANOVA, nosepoke response latencies were specifically compared between baseline and deliberation laser delivery sessions to determine whether laser delivery (which was initiated $0.5 \mathrm{~s}$ before nosepoke illumination) affected this aspect of behavior. Latencies to press levers in free choice trials were defined as the duration between the nosepoke to initiate a trial and a subsequent lever press. These choice latencies were analyzed using a three-factor repeated-measures ANOVA with lever identity (small, "safe" lever vs large, "risky" lever), session condition, and block as within-subject factors. Effects of BLA inhibition on omissions during free and forced choice trials were analyzed using a paired $t$ test with session condition as the within-subjects factor.

To better understand the effects of BLA inhibition during task phases in which inhibition significantly affected choice behavior, additional analyses were conducted to determine whether optogenetic manipulations altered the degree to which feedback from past trials influenced subsequent choices. Specifically, this analysis provided a measure of how BLA inhibition affected the likelihood of choosing the large, risky outcome upon receipt of the large reward in the absence of punishment on the previous trial (win-stay performance) versus the likelihood of choosing the large, risky outcome upon receipt of the large reward accompanied by punishment on the previous trial (lose-shift performance) (Bari et al., 2011; St Onge et al., 2011). To perform this analysis, choices were categorized according to the outcome of the previous trial (large, punished outcome vs large, unpunished outcome). Win-stay performance was calculated as the number of trials in which a rat chose the large, risky lever after receipt of a large, unpunished outcome (win), divided by the total number of free choice trials in which the rat received a large, unpunished outcome. Similarly, lose-shift performance was calculated as the number of trials within each free choice block in which a rat chose the small, safe lever after receipt of a large, punished outcome (lose), divided by the total number of free choice trials in which the rat received a large, punished outcome. Effects of BLA inhibition on the percentage of winstay and lose-shift trials were each analyzed using paired $t$ tests with session (baseline vs inhibition) as the within-subjects factor.

Shock threshold intensities for the laser delivery or no laser delivery sessions were averaged across the two test days. Analysis of shock intensity thresholds was conducted using a two-factor repeated-measures ANOVA with session (BLA inhibition vs no inhibition) and type of motor response as the within-subjects factors. To eliminate the possibility that the order of the test sessions on each day contributed to differences in shock reactivity thresholds, another repeated-measures ANOVA was conducted using the same within-subjects factors and also included session order as a between-subjects factor. If either of these parent ANOVAs resulted in main effects or significant interactions, additional repeatedmeasures ANOVA or paired $t$ tests were performed to determine the source of significance.

\section{Results}

\section{In vitro electrophysiology}

In slices from rats injected with AAV5-CaMKII $\alpha$-eNpHR3.0mCherry, BLA neurons expressing mCherry were identified with epifluorescence microscopy and recordings were made using conventional whole-cell recording techniques (see Materials and Methods). mCherry-positive BLA neurons $(n=11)$ had a mean whole-cell capacitance of $149 \pm 14.9 \mathrm{pF}$. A subset of these neurons was filled with biocytin, immunolabeled with Alexa-594, and imaged with 2-photon-meditated epifluorescence microscopy. Cells examined in this manner were all multipolar and had dense local dendritic branches within the BLA (Fig. 2A). Collectively, these features are consistent with effective transduction of glutamatergic BLA principal neurons. A $1 \mathrm{~s}$ activation of eNpHR3.0 in mCherry-positive BLA neurons voltage-clamped at $-70 \mathrm{mV}$ (see Materials and Methods) produced a clear outward current, which had a peak amplitude of $117 \pm 29.6 \mathrm{pA}$, obtained within $\sim 100$ ms of activation, and a mean amplitude of $80.0 \pm$ $20.8 \mathrm{pA}$, as observed during the last $200 \mathrm{~ms}$ of activation (Fig. 2B). Identical stimulation in current clamp $(I=0)$ produced a maximum hyperpolarization of $-16 \pm 3.1 \mathrm{mV}$ (also obtained within $\sim 100$ ms of activation) and a mean hyperpolarization of $-9.0 \pm$ $2.0 \mathrm{mV}$ as observed during the last $200 \mathrm{~ms}$ of activation (Fig. 2C). This hyperpolarization was sufficient to completely silence 9 of 11 cells tested when firing under a 100-200 pA load (Fig. 1D). Firing rate was slowed, but not eliminated, in the other two cells. Collectively, these results demonstrate that sustained activation of eNpHR3.0 produces robust functional inhibition of BLA principal neurons.

\section{Histology}

Of the 22 rats that received the viral vector containing eNpHR3.0 for optogenetic manipulations, 1 died during surgery and 5 were killed during training due to detached headcaps. Of the remaining 16 rats, 3 were excluded due to off-target fiber placements (too ventral; $n=1$ ) or lack of eNpHR3.0 expression in one hemisphere $(n=2)$. Figure $3 A$ displays the maximum (light gray) and minimum (dark gray) spread of the virus, and Figure $3 B$ depicts the location of optic fiber tips of rats that were included in the final data analysis. A representative placement of a fiber tip in the BLA with eNpHR3.0 expression is shown in Figure 3C.

Of the 9 rats that received the viral vector containing mCherry alone, 1 died during surgery and 4 were killed during training due to detached headcaps, resulting in a final $n=4$. Figure $3 D$ displays the maximum (light gray) and minimum (dark gray) spread of the virus, and Figure $3 E$ shows the location of optic fiber tips of control rats that were included in the final data analysis.

\section{Optogenetic BLA inhibition during decision making in eNpHR3.0 rats}

$B L A$ inhibition during deliberation

Optogenetic inhibition of the BLA during deliberation $(n=12)$ caused a significant decrease in choice of the large, risky outcome (decreased risky choice; inhibition, $F_{(1,11)}=14.57, p<0.01$; inhibition $\times$ block interaction, $F_{(2,22)}=10.29, p<0.01$; Fig. $4 A$ ). Importantly, this effect was only observed in blocks of trials in which there was a risk of punishment: although there was no effect of inhibition in Block $1\left(t_{(11)}=-1.27, p=0.23\right)$, BLA inhibition decreased choice of the large, risky outcome in both Block $2\left(t_{(11)}=4.51, p<\right.$ $0.01)$ and Block $3\left(t_{(11)}=2.16, p=0.05\right)$.

Additional analyses were performed to determine whether BLA inhibition during deliberation affected the percentage of 


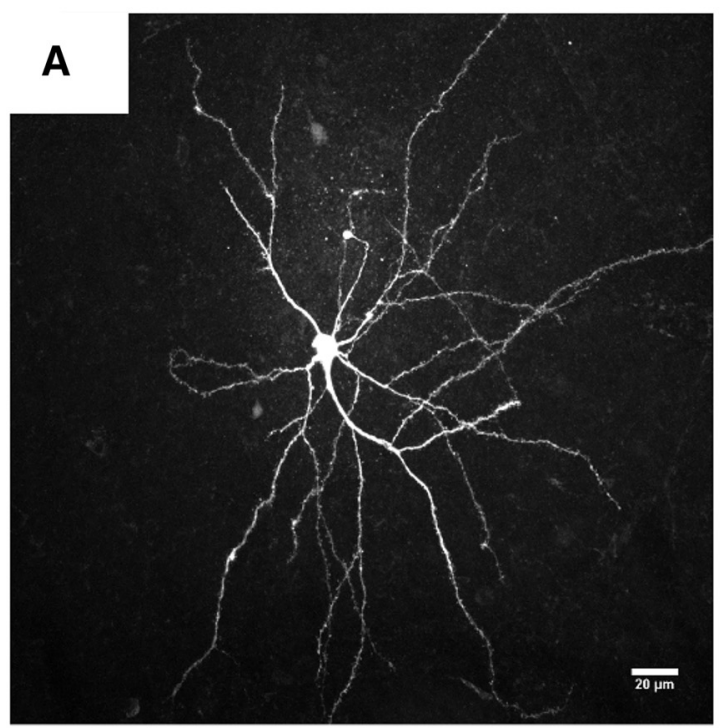

B

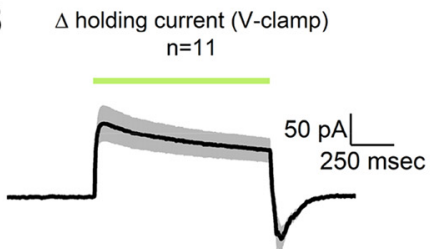

D

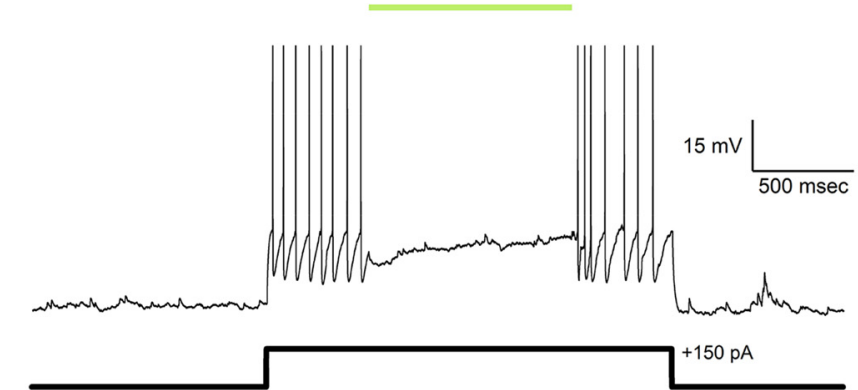

Figure 2. Functional validation of eNpHR3.0 in the BLA. $A$, Two-photonz-series projection of a mCherry-positive BLA neuron filled with biocytin and immunolabeled with Alexa-594. $B$, Activation of eNpHR3.0 produced a clear outward current in mCherry-positive BLA neurons $(n=11)$ voltage-clamped at $-70 \mathrm{mV}$. Green bar represents optical stimulation. Shaded area around the average trace represents the SEM. C, Identical activation of eNpHR3.0 in current clamp produced robust hyperpolarization $(n=11)$. A brief, mild, rebound depolarization was apparent immediately after optical stimulation. This current, likely mediated by HCN channels (Womble and Moises, 1993; Park et al., 2007, 2011; Giesbrecht et al., 2010), had a mean amplitude in current clamp of $4.7 \pm 1.3$ $\mathrm{mV}$ and was almost always insufficient to drive the cells to threshold for action potentials. Green bar represents optical stimulation. Shaded area around the average trace represents the SEM. A small subset of individual sweeps that did have at least one rebound action potential after sustained eNpHR3.0-mediated hyperpolarization were removed from the average traces presented in $\boldsymbol{B}, \boldsymbol{C}$. $D$, A representative $m$ Cherry-positive BLA neuron that was current-clamped at $0 \mathrm{pA} \mathrm{shows} \mathrm{an} \mathrm{increase} \mathrm{in} \mathrm{firing} \mathrm{rate} \mathrm{upon} \mathrm{injection} \mathrm{of} \mathrm{a} 150 \mathrm{pA}$ current pulse, which is effectively suppressed during activation of eNpHR3.0.

A

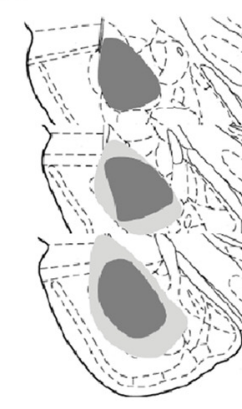

D

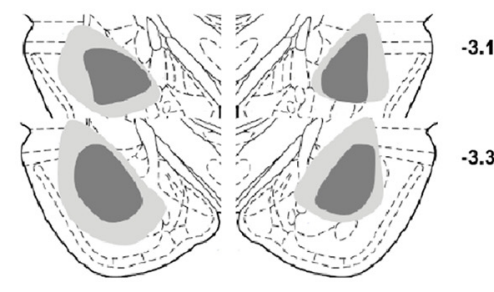

B

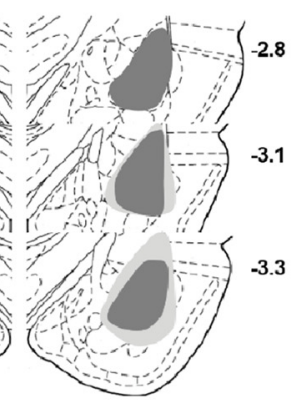

$E$
C
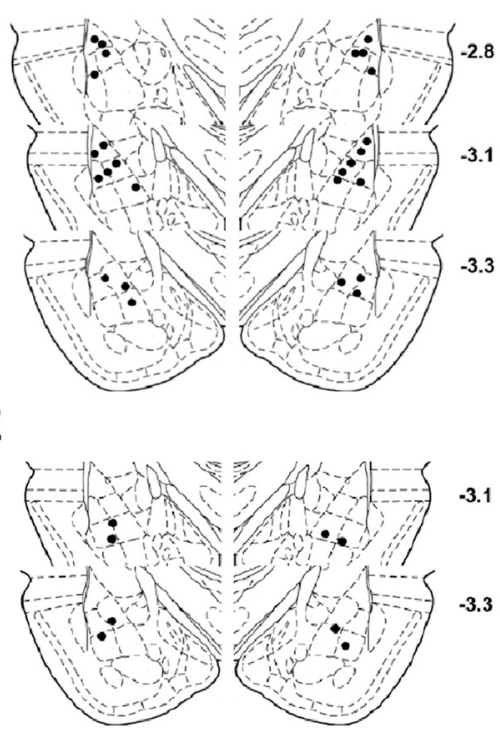

Figure 3. eNpHR3.0 expression and optic fiber placement in the BLA. A, Schematic depicting the maximum (light gray) and minimum (dark gray) spread of eNpHR3.0 expression in the BLA. $B$, Optic fiber placements in the BLA. Black circles represent the tips of the optic fibers. C, Representative micrograph depicting eNpHR3.0 expression and the tip of the optic fiber in the BLA. Dashed white line indicates the borders of the BLA. D, Schematic depicting the maximum (light gray) and minimum (dark gray) spread of mCherry expression in the BLA of control rats. $E$, Optic fiber placements in the BLA in control rats. Black circles represent the tips of the optic fibers.

win-stay and lose-shift trials (Fig. 4B). Because a substantial number of rats $(n=9)$ failed to choose the large, risky outcome in the second and third blocks, win-stay and lose-shift trials could not be compared across the different punishment probabilities. This was also an issue for baseline performance as some rats only chose the small, safe outcome in the third block. To circumvent this issue, the percentages of win-stay and lose-shift trials were calculated using the sum of each of these trial types across both blocks. There was no effect of inhibition on the percentage of win-stay trials $\left(t_{(8)}=1.61, p=0.15\right)$, but there was a near significant increase in the percentage of lose-shift trials $\left(t_{(9)}=-1.99\right.$, $p=0.08)$. In the win-stay analysis, 3 rats were excluded because they either never chose the large, risky outcome or never encountered a trial in which they chose the large, risky outcome and 
A

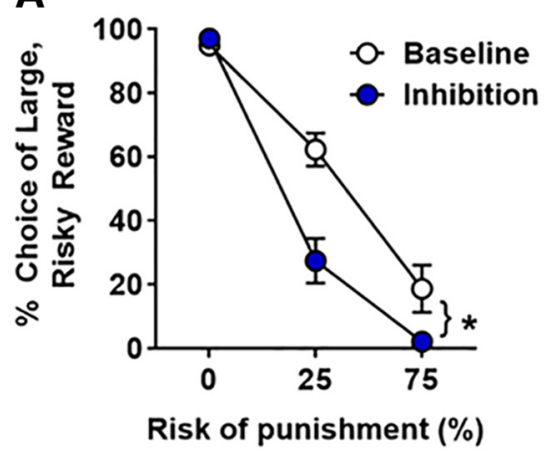

B

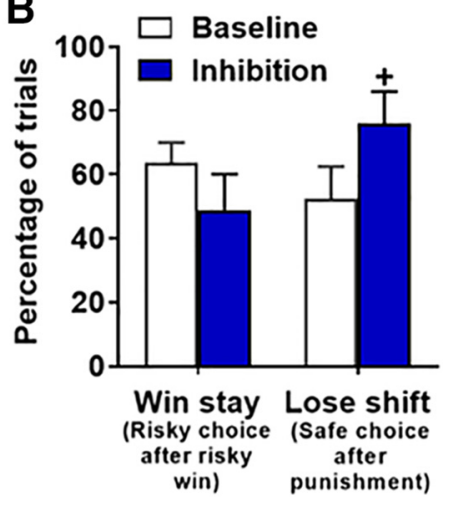

Figure 4. BLA inhibition during deliberation decreases risky choice. $\boldsymbol{A}, \mathrm{BLA}$ inhibition decreases choice of the large, risky outcome. $\boldsymbol{B}$, There were no effects of BLA inhibition on win-stay trials. In contrast, there was a near-significant increase in lose-shift trials upon BLA inhibition. Data are mean \pm SEM. ${ }^{*}$ Significant difference. ${ }^{+}$Trend $(p=0.08)$ toward a significant difference between inhibition and baseline (no laser) conditions.

received the large reward without punishment. Similarly, in the lose-shift analysis, 2 rats were excluded because they never selected the large, risky outcome. This modest increase in lose-shift trials suggests that BLA inhibition slightly increased the likelihood for rats to shift their choice to the small, safe outcome after receiving a large reward accompanied by punishment. Collectively, these results show that BLA inhibition during the period in which rats deliberated between the two available options caused an increase in risk aversion.

Because laser delivery began just before the deliberation period, additional analyses were conducted to determine whether BLA inhibition affected rats' latency to nosepoke to trigger lever extension. Although there was no main effect of inhibition (baseline mean \pm SEM: $1.27 \pm 0.12$, inhibition mean \pm SEM: $1.23 \pm$ $\left.0.16 ; F_{(1,11)}=0.05, p=0.82\right)$, there was a trend toward a significant inhibition $\times$ block interaction $\left(F_{(2,22)}=3.10, p=0.07\right)$, with BLA inhibition causing a slight decrease in latency to nosepoke, particularly in Block 3 (mean \pm SEM of $1.87 \pm 0.24 \mathrm{~s}$ for baseline; mean \pm SEM of $1.48 \pm 0.15 \mathrm{~s}$ for inhibition). In addition, latencies to press levers on free choice trials were analyzed only in Block 2 of the session due to rats' near-exclusive preference for one lever over the other in Blocks 1 and 3 (i.e., the large, risky lever in Block 1 and small, safe lever in Block 3). Latencies to press the small, safe lever (baseline mean \pm SEM: $0.84 \pm 0.09$, inhibition mean \pm SEM: $0.71 \pm 0.05)$ were faster than latencies to press the large, risky lever (baseline mean \pm SEM: $1.23 \pm 0.19$, inhibition mean \pm SEM: $\left.1.0 \pm 0.09 ; F_{(1,7)}=22.18, p<0.01\right)$, but this pattern of behavior was not affected by BLA inhibition (inhibition, $F_{(1,7)}=1.96, p=0.20$; inhibition $\times$ lever identity, $F_{(1,7)}=3.61$, $p=0.10)$. Finally, there was no effect of BLA inhibition during deliberation on omissions in either the forced choice trials (baseline mean \pm SEM: $4.86 \pm 0.1 .28$, inhibition mean \pm SEM: $6.25 \pm$ $1.09 ; t_{(11)}=-0.87, p=0.44$ ) or the free choice trials (baseline mean \pm SEM: $1.63 \pm 0.051$, inhibition mean \pm SEM: $1.98 \pm$ $\left.1.19 ; t_{(11)}=-0.26, p=0.80\right)$.

BLA inhibition during delivery of the small, safe outcome Optogenetic inhibition of the BLA during delivery of the small, safe outcome $(n=10)$ had no effect on choice of the large, risky outcome (inhibition, $F_{(1,9)}=0.09, p=0.77$; inhibition $\times$ block, $F_{(2,18)}=1.73, p=0.21$; Fig. $5 A$ ). Additionally, inhibition had no effect on omissions during forced choice trials (baseline mean \pm SEM: $4.86 \pm 0.1 .28$, inhibition: $4.17 \pm 1.96 ; t_{(9)}=-0.32, p=$ 0.76 ) or during free choice trials (baseline: $1.63 \pm 0.051$, inhibi- tion: $\left.2.17 \pm 1.34 ; t_{(9)}=-0.91, p=0.39\right)$. Hence, BLA inhibition during delivery of the small, safe outcome did not alter choice behavior.

\section{$B L A$ inhibition during delivery of the large, unpunished outcome}

Similarly, there was no effect of BLA inhibition during the large, unpunished outcome $(n=9)$ on choice behavior (inhibition, $F_{(1,8)}=0.45, p=0.52$; inhibition $\times$ block, $F_{(2,16)}=0.30, p=0.74$; Fig. $5 B$ ). There were also no effects of inhibition on omissions during forced choice trials (baseline mean \pm SEM: $4.86 \pm 1.28$, inhibition mean \pm SEM: $\left.2.78 \pm 1.20 ; t_{(8)}=0.50, p=0.63\right)$ or free choice trials (baseline mean \pm SEM: $1.63 \pm 0.051$, inhibition mean \pm SEM: $\left.1.67 \pm 0.75 ; t_{(8)}=-1.0, p=0.35\right)$. Collectively, these findings indicate that BLA inhibition during delivery of the large, unpunished outcome did not affect choice behavior.

BLA inhibition during delivery of the large, punished outcome In contrast to BLA inhibition during delivery of the large, unpunished outcome, inhibition during delivery of the large, punished outcome $(n=10)$ significantly increased choice of the large, risky outcome (inhibition, $F_{(1,9)}=82.75, p<0.01$; inhibition $\times$ block, $F_{(1,9)}=39.22, p<0.01$; Fig. $\left.6 A\right)$. It is important to note that this analysis only used choice behavior in the $25 \%$ and $75 \%$ blocks from baseline and laser delivery sessions, as they were the only blocks in which BLA inhibition could occur.

Given the significant effects of BLA inhibition during this phase of the task, additional analyses were performed to determine how this manipulation affected the percentage of win-stay and loseshift trials (Fig. 6B). Because many rats exclusively chose the small, safe outcome in the third block at baseline, it was not possible to compare win-stay and lose-shift trials across the punishment probabilities. Consequently, the percentages of win-stay and lose-shift trials were calculated using the sum of each trial type across both blocks. There was no effect of BLA inhibition on the percentage of win-stay trials $\left(t_{(9)}=-0.44, p=0.67\right)$; however, there was a significant decrease in the percentage of loseshift trials $\left(t_{(9)}=3.02, p=0.01\right)$ compared with baseline. Thus, BLA inhibition during delivery of the large, punished outcome caused rats to increase the likelihood of choosing the large, risky outcome, even when they were punished for this choice on the preceding trial.

There were no effects of BLA inhibition on omissions during free choice trials (baseline mean \pm SEM: $1.63 \pm 0.051$, inhibition mean \pm SEM: $\left.0.83 \pm 0.57 ; t_{(9)}=0.09, p=0.93\right)$, although inhibition did cause a significant decrease in omissions during forced choice trials compared with baseline conditions (baseline mean \pm SEM: $4.86 \pm 1.28$, inhibition mean \pm SEM: $0.10 \pm 0.10$; $\left.t_{(9)}=2.56, p=0.03\right)$. Finally, latencies to press levers on the free choice trials were analyzed for Blocks 2 and 3. Although there was an overall main effect of BLA inhibition $\left(F_{(1,7)}=8.14, p=0.03\right)$, there was neither a main effect of lever identity $\left(F_{(1,7)}=2.69, p=\right.$ $0.15)$ nor significant inhibition $\times$ lever identity $\left(F_{(1,7)}=2.47, p=\right.$ $0.16)$, inhibition $\times$ block $\left(F_{(1,7)}<0.01, p=0.95\right)$, or inhibition $\times$ lever identity $\times$ block $\left(F_{(1,7)}=0.70, p=0.43\right)$ interactions. These results indicate that, relative to baseline conditions (Block 2: small lever: $0.84 \pm 0.09$, large, risky lever: $1.23 \pm 0.19$; 
A

\section{Small, safe outcome}

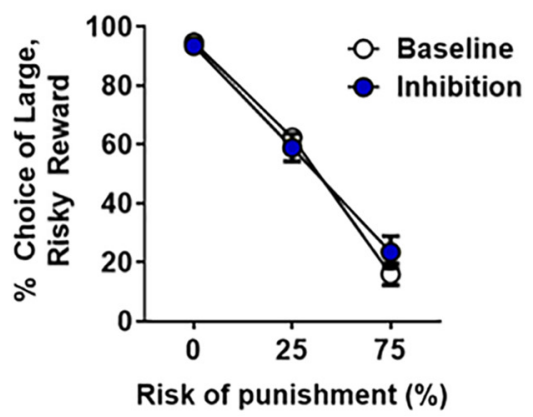

B

Large, unpunished outcome

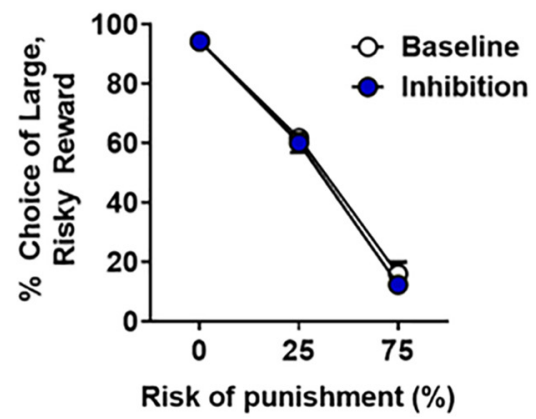

C

\section{Intertrial interval}

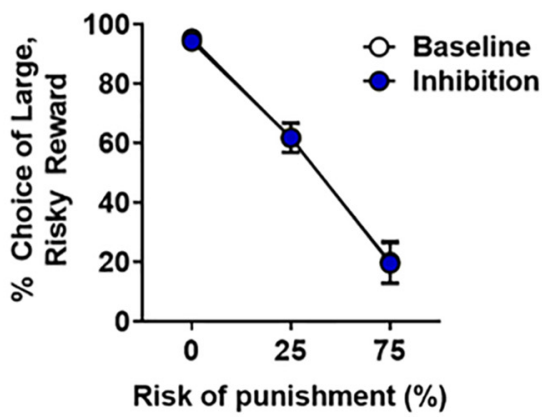

Figure 5. BLA inhibition has no effect on risky choice during other task phases. $A, B L A$ inhibition during delivery of the small, safe outcome did not affect choice of the large, risky outcome. $B$, BLA inhibition during delivery of the large, unpunished outcome had no effect on choice of the large, risky outcome. C, BLA inhibition during the ITI had no effect on choice of the large, risky outcome. Data are mean \pm SEM.

Block 3: small lever: $0.80 \pm 0.09$, large, risky lever: $1.22 \pm 0.24)$, latencies to press levers during free choice trials were faster when the BLA was inhibited (Block 2: small lever: $0.73 \pm 0.13$, large, risky lever: $0.69 \pm 0.07$; Block 3: small lever: $0.56 \pm 0.04$, large, risky lever: $0.78 \pm 0.08$ ) during delivery of the large, risky outcome.

\section{BLA inhibition during shock threshold testing}

Rather than affecting processes related to risk taking per se, the effects of BLA inhibition during delivery of the large, punished outcome could have been due to an inhibition-induced decrease in shock sensitivity. To address this, a subset of rats $(n=6)$ was tested in a behavioral assay that evaluates the thresholds at which selective motor responses (as described in Materials and Methods) are elicited by shock delivery. These thresholds were obtained under laser and no laser (inhibition vs no inhibition, respectively) conditions (Fig. $6 C$ ). A two-factor repeated-measures ANOVA revealed neither a main effect of inhibition $\left(F_{(1,5)}=\right.$ 4.00, $p=0.10)$ nor an inhibition $\times$ motor response interaction $\left(F_{(2,10)}=0.04, p=0.96\right)$. Thus, the increase in risky choice during sessions in which BLA inhibition occurred during delivery of the large, punished outcome cannot be accounted for by a decrease in footshock sensitivity.

\section{$B L A$ inhibition during ITIs}

Optogenetic inhibition of the BLA during the ITI $(n=13)$ had no effect on choice of the large, risky outcome (inhibition, $F_{(1,12)}=$ $0.01, p=0.91$; inhibition $\times$ block, $F_{(2,24)}=0.02, p=0.98$; Fig. $5 C)$. Similarly, BLA inhibition during ITIs did not affect omissions during forced choice trials (baseline mean \pm SEM: $4.86 \pm$ 1.28 , inhibition mean \pm SEM: $4.17 \pm 1.49 ; t_{(12)}=0.3, p=0.77$ ) but caused a near significant increase in omissions during free choice trials (baseline mean \pm SEM: $1.63 \pm 0.051$, inhibition mean \pm SEM: $\left.5.33 \pm 1.48 ; t_{(12)}=-2.04, p=0.06\right)$.

\section{Laser delivery in the BLA during decision making in control rats}

To ensure that the effects of BLA inhibition were not due to laser delivery alone, another group of rats received intra-BLA microinjections of a vector carrying mCherry alone and were then trained in the RDT. Because BLA inhibition only altered choice behavior during deliberation and delivery of the large, punished outcome in eNpHR3.0 rats, control rats only received laser delivery during these two phases (in separate sessions, in a randomized order across rats).
Laser delivery during deliberation

Laser delivery in the BLA during deliberation $(n=4)$ had no effect on choice of the large, risky outcome compared with baseline conditions (laser delivery, $F_{(1,3)}<0.1, p=0.98$; laser delivery $\times$ block, $F_{(2,6)}=2.22, p=0.19$; Fig. $\left.7 A\right)$. There was no main effect of laser delivery on latency to nosepoke to initiate lever extension (baseline mean \pm SEM: $0.91 \pm 0.13$, laser delivery mean \pm SEM: $\left.1.01 \pm 0.19 ; F_{(1,3)}=2.33, p=0.23\right)$; however, it appeared that under laser delivery conditions, latency to nosepoke did increase across the session $\left(F_{(2,6)}=7.70, p=0.02\right)$. Although there was a trend toward a significant effect of laser delivery on omissions during forced choice trials $\left(t_{(3)}=-2.82, p=0.07\right)$, this was due to the fact that there were no omissions under laser delivery (baseline mean \pm SEM: $1.40 \pm 0.49$, laser delivery mean \pm SEM: $0.0 \pm 0.0$ ). There were no effects of laser delivery on omissions during free choice trials (baseline mean \pm SEM: $0.21 \pm 0.21$, laser delivery mean \pm SEM: $\left.0.84 \pm 0.48 ; t_{(3)}=1.00, p=0.39\right)$. Collectively, these results indicate that laser delivery alone during deliberation did not affect risky decision making in control rats.

A three-factor repeated-measures ANOVA was conducted to compare the effects of laser delivery between eNpHR3.0 and control vector rats. There was a main effect of vector group $\left(F_{(1,14)}=\right.$ $8.36, p=0.01)$ and a near significant main effect of laser delivery $\left(F_{(1,14)}=4.12, p=0.06\right)$ and laser delivery $\times$ vector group interaction $\left(F_{(1,14)}=3.96, p=0.07\right)$. Although there was no laser delivery $\times$ block interaction $\left(F_{(2,28)}=1.83, p=0.18\right)$, there was a significant laser delivery $\times$ vector group $\times$ block interaction $\left(F_{(2,28)}=4.96, p=0.01\right)$. These results indicate that, relative to baseline conditions, laser delivery in the BLA decreased choice of the large, risky outcome specifically in the eNpHR3.0 rats.

Laser delivery during delivery of the large, punished outcome There was also no effect of laser delivery during delivery of the large, punished outcome $(n=4)$ on choice of the large, risky outcome (laser delivery, $F_{(1,3)}=0.24, p=0.66$; laser delivery $X$ block, $F_{(2,6)}=0.91, p=0.45$; Fig. $7 B$ ). There was a trend toward a significant effect of laser delivery on omissions during forced choice trials $\left(t_{(3)}=-2.82, p=0.07\right)$; however, this was due the absence of omissions under laser delivery (baseline mean \pm SEM: $1.40 \pm 0.49$, laser delivery mean \pm SEM: $0.0 \pm 0.0)$. There were no differences in omissions during free choice trials between laser delivery and baseline conditions (baseline mean \pm SEM: $0.21 \pm 0.21$, laser delivery mean \pm SEM: $1.25 \pm 0.42 ; t_{(3)}=$ $1.67, p=0.19$ ). Hence, laser delivery alone into the BLA during 
A

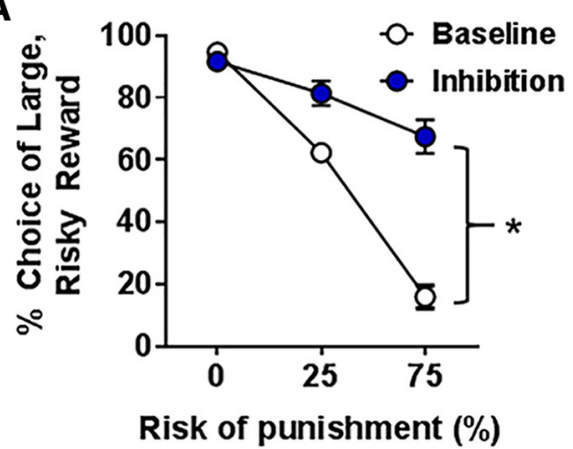

B

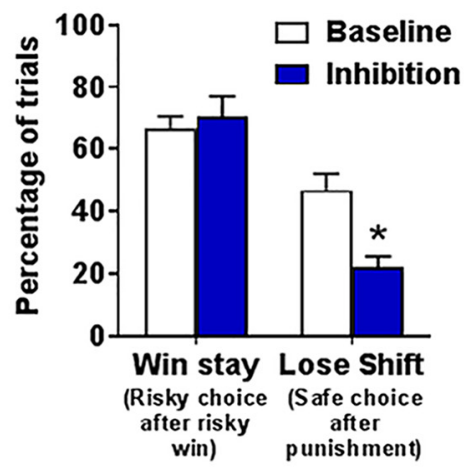

C

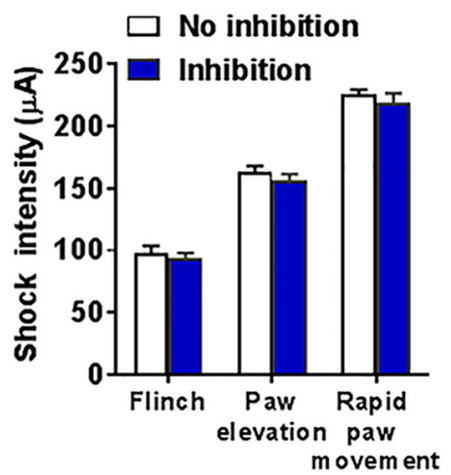

Figure 6. BLA inhibition during delivery of the large, punished outcome increases risky choice. $A$, BLA inhibition increased choice of the large, risky outcome. $B$, There was no effect of BLA inhibition on win-stay performance. In contrast, BLA inhibition decreased lose-shift performance. C, BLA inhibition did not alter the intensity thresholds at which shock elicited a flinch, elevation of 1 or 2 paws, or rapid movement of 3 or all paws. Data are mean \pm SEM. *Significant difference between inhibition and baseline (no laser) conditions.

the large, punished outcome had no effect on risky decision making in control rats.

A three-factor repeated-measures ANOVA was used to compare the effects of laser delivery in the BLA on choice performance between eNpHR3.0 and control vector rats. Although there was not a main effect of vector group $\left(F_{(1,12)}=0.41, p=0.54\right)$, there was a main effect of laser delivery $\left(F_{(1,12)}=21.33, p<0.01\right)$. Further, there were significant laser delivery $\times$ vector group $\left(F_{(1,12)}=13.85, p<\right.$ $0.01)$, laser delivery $\times$ block $\left(F_{(2,24)}=14.30, p<0.01\right)$, and laser delivery $\times$ vector group $\times \operatorname{block}\left(F_{(2,24)}=18.15, p<0.01\right)$ interactions. Collectively, these results indicate that, relative to baseline conditions, laser delivery in the BLA decreased choice of the large, risky outcome specifically in the eNpHR3.0 rats.

\section{Discussion}

Decision making involves coordination of multiple cognitive functions to generate choice behavior. Although there is a grow- ing body of literature delineating the brain regions governing decision making, less is known about how and when such brain regions are engaged during the decision process. The current study demonstrates that the BLA plays distinct roles during different components of risky decision making. Whereas optogenetic inhibition of the BLA during deliberation resulted in a decrease in choice of the large, risky outcome (decreased risky choice), BLA inhibition during delivery of the large, punished outcome had the opposite effect (increased risky choice). These effects were specific to the task phase in which inhibition occurred because BLA inhibition had no effect on choice behavior during delivery of the small, safe outcome, the large, unpunished outcome, or the ITI. Further, there were no effects of laser delivery into the BLA during deliberation or delivery of the large, punished outcome in control rats (in the absence of eNpHR3.0).

The overall finding that BLA manipulation alters choice performance during risky decision making is consistent with previous studies implicating this structure in cost/benefit decision making. In a risky decision-making task involving choices between a small, certain food reward and a large, probabilistic food reward, pharmacological inactivation of BLA decreased choice of the large, probabilistic reward, but only at probabilities at which it was more profitable to choose this reward (Ghods-Sharifi et al., 2009). Consistent with this, BLA lesions induce a pattern of disadvantageous choice behavior in another rodent model of risky decision making designed to simulate the Iowa Gambling Task (Zeeb and Winstanley, 2011). More recently, we showed that BLA lesions increase risky choice in the RDT (Orsini et al., 2015a), and control experiments suggested that this increase was due to impaired integration of reward magnitude and punishment-related information. Given the complexity of the decision-making process, however, the use of lesions and pharmacological inactivation, while informative, may obscure a complete understanding of how the BLA is engaged during the course of individual decisions.

To circumvent this issue, the current study used optogenetics to selectively inhibit the BLA during distinct phases of the decision-making process. In contrast to effects of permanent BLA lesions (Orsini et al., 2015a), optogenetic inhibition caused both an increase and decrease in risky choice depending on the time point at which inhibition occurred. These results suggest that the contribution of the BLA to risky choice is not uniform, but instead that it may function in different capacities even over the course of a few seconds of a decision-making trial. During deliberation, various sources of information must be assimilated to bias behavior toward a specific choice. In particular, information about the anticipated rewarding aspects of each potential outcome must be integrated and weighed against the negative/adverse aspects of those outcomes. BLA inhibition during this period interfered with this integrative process such that choices were shifted away from the large, risky outcome. One possibility is that this is due to a loss of reward magnitude information, although this seems unlikely given that choice behavior was intact in the first block of trials (in which there was no risk of punishment). Alternatively, and consistent with the slight increase in lose-shift trials, BLA inhibition may have augmented the salience of the punishment associated with the large reward. This also seems unlikely, however, given that lesions and pharmacological inactivation of the BLA reduce fear expression in other contexts (Helmstetter and Bellgowan, 1994; Maren et al., 1996). A final, and more likely possibility, is that BLA inhibition during deliberation may have attenuated the incentive salience of anticipated outcomes and, consequently, the ability to bias action selection toward more salient rewards. Hence, the BLA may be important 
for tagging available outcomes based on their incentive salience (i.e., to favor larger, albeit riskier, outcomes). In the absence of an intact BLA, the punishment history and/or aversive properties of these outcomes prevail and drive choice behavior.

In contrast, the increase in risk taking following BLA inhibition during delivery of the large, punished outcome suggests that the BLA is engaged in a manner different from that during deliberation. Incorporating feedback about outcomes of past choices to guide future choice is a critical aspect of adaptive decision making. The BLA has long been implicated in encoding and representing aversive properties of stimuli in Pavlovian and instrumental learning tasks (Wassum and Izquierdo, 2015). Thus, inhibition during delivery of the large, punished outcome may have prevented the BLA from encoding the punishing aspects of this outcome and therefore impaired the ability to use this information as feedback to adjust future choice behavior. This would result in choice performance being driven by rewarding properties of this outcome, regardless of whether its delivery was accompanied by footshock. This interpretation is supported by the significant decrease in lose-shift trials such that rats continued to choose the large, risky outcome despite having been punished on the preceding trial. Importantly, the effects of BLA inhibition during this phase were not due to alterations in shock sensitivity, as there were no changes in thresholds at which shock-induced motor responses were elicited. This is consistent with previous work showing that BLA lesions do not affect discrimination between punished and unpunished rewards of the same magnitude (Orsini et al., 2015a) and when considered together, demonstrates that the BLA is not necessary for encoding shock alone. Collectively, these data suggest that when a rewarding outcome is accompanied by an adverse consequence, the BLA may be responsible for encoding the negative aspects of that outcome that can then be used as feedback during future deliberation.

The idea that the BLA functions in a heterogeneous manner during risky decision making is consistent with previous work showing that BLA neurons that encode aversive and appetitive outcomes are largely segregated into distinct populations (Schoenbaum et al., 1998; Paton et al., 2006; Belova et al., 2007, 2008; Shabel and Janak, 2009; Sangha et al., 2013; Zhang et al., 2013; Namburi et al., 2015; Beyeler et al., 2016). This suggests that the functional heterogeneity of the BLA during risky decision making could arise from distinct neuronal populations representing incentive salience (positive-value neurons) versus aversive properties (negative-value neurons) of choice outcomes. The current data further suggest that these separate populations may be differentially engaged depending on the phase of the decision process. Thus, positive-value neurons may be particularly important during the deliberative process for signaling the incentive salience of possible outcomes, whereas negative-value neurons may be critical for incorporation of negative feedback into future action plans. Of course, it should be recognized that there are also neurons within the BLA that represent both aversive and appetitive outcomes (Paton et al., 2006; Belova et al., 2008; Shabel and Janak, 2009; Sangha et al., 2013), and which might contribute to both deliberative and negative feedback processes. It is not clear, however, whether these populations of neurons interact with one another and, if so, when and where this interaction occurs.
If, indeed, distinct populations of BLA neurons are differentially engaged during decision making, how might they ultimately affect choice behavior? One possibility is that positive- and negative-value neurons have divergent and nonoverlapping downstream targets. Indeed, BLA neurons that project to the nucleus accumbens (NAc) selectively support reward conditioning, whereas BLA neurons that project to the central nucleus of the amygdala (CeA) selectively support fear conditioning (Namburi et al., 2015; Beyeler et al., 2016). Whereas the BLA-NAc projection is implicated in risky decision making (St Onge et al., 2012), the contribution of the BLA-CeA circuit is unknown. It is also possible that putative positive- and negative-value BLA neurons modulate risky choice through divergent projections to the core and shell subregions of the NAc, respectively. This hypothesis is consistent with the canonical theory that the NAc core (NAcC) is important for facilitating approach behavior (Di Ciano et al., 2001; Ambroggi et al., 2011; Saunders and Robinson, 2012), whereas the NAc shell (NAcSh) is required for suppressing inappropriate behavior (Di Ciano et al., 2008; Floresco et al., 2008; Stopper and Floresco, 2011; Dalton et al., 2014). This functional dichotomy extends to instrumental tasks involving conflict or punishment: NAcSh inactivation increases punished responding (Piantadosi et al., 2017) and decreases avoidance responses (Fernando et al., 2014), whereas NAcC inactivation decreases overall reward-seeking, regardless of accompanying punishment (Piantadosi et al., 2017). Further evidence indicates that these distinct functions are modulated by BLA input. For example, activation of the BLA-NAcC pathway drives reward-seeking behavior (Ambroggi et al., 2008; Stuber et al., 2011; Namburi et al., 2015), and interruption of this circuit impairs reward conditioning and decision making (Ambroggi et al., 2008; Stuber et al., 2011; St Onge et al., 2012). In contrast, the BLA-NAcSh, but not the BLA-NAcC, pathway supports active avoidance behavior (Ramirez et al., 2015). Thus, positive-encoding BLA neurons may contribute to the deliberative process via their downstream connections with the $\mathrm{NAcC}$, and negative-encoding BLA neurons may provide negative feedback information through their interactions with the NAcSh. Interestingly, it has been proposed that networks of inhibitory BLA interneurons may play a permissive role in determining which neuronal circuits are engaged during motivated behavior (Janak and Tye, 2015), which could allow flexible shifts in choice behavior as reward or punishment contingencies change.

Although not mutually exclusive, positive-encoding BLA neurons may alternatively mediate the deliberative process through their projections to the orbitofrontal cortex (OFC). Indeed, OFC lesions decrease risk taking in the RDT (Orsini et al., 2015a), mimicking the effects of optogenetic inhibition of the BLA during 
deliberation. Lending support to this hypothesis, functional disconnection of the BLA and OFC retarded learning optimal choice behavior in a rodent gambling task (Zeeb and Winstanley, 2013). Although this manipulation was not specific to deliberation, it is consistent with the effects of OFC lesions in the RDT, which, as stated above, recapitulate the effects of optogenetic BLA inhibition during the deliberation period. Finally, previous work shows that the ability of the OFC to represent incentive values of cues (e.g., rewarding vs aversive) depends on input from the BLA (Schoenbaum et al., 2003). Thus, positive-encoding neurons in the BLA may transmit the rewarding properties of the large, risky outcome to the OFC, which can guide subsequent choice via its own projections to the BLA (Saddoris et al., 2005) or ventral striatum (Gourley et al., 2013). A critical next step will therefore be to selectively inhibit distinct BLA efferent pathways during deliberation to further understand how information is transmitted during this phase of the decision process.

Finally, it is important to note that these experiments were conducted only in male rats. Given that there are sex differences in risk taking in the RDT (Orsini et al., 2016) and that the amygdala is sexually dimorphic in both size and function (Cahill et al., 2001, 2004; Goldstein et al., 2001; Kilpatrick et al., 2006), it is possible that these same manipulations in females would yield different results. Interestingly, a recent study examining sex differences in decision making reported greater dopamine D2 receptor (D2R) mRNA expression in the BLA of females compared with males (Georgiou et al., 2017). Although D2R mRNA expression in neither sex correlated with choice behavior in this task, D2R mRNA expression in the NAc is negatively correlated with risky choice preference in the RDT in males (Mitchell et al., 2014). Although it is completely unknown whether this relationship also exists in the BLA in females in the RDT, it is conceivable that the increased risk aversion in females in the RDT (Orsini et al., 2016) may be associated with the decreased D2R mRNA expression in females observed by Georgiou et al. (2017). Collectively, these findings support the hypothesis that the BLA may be differentially engaged in males and females during risk taking and, thus, that optogenetic manipulation of the BLA in females may reveal important sex differences in its role in the decision process.

To our knowledge, this study is the first to demonstrate multiple roles for the BLA in decision making depending on the phase of the decision process engaged. These results highlight the need to use more temporally targeted manipulations to understand the neural circuitry supporting complex cognitive operations. More importantly, these findings provide a more refined understanding of how the BLA contributes to risk-based decision making, and a foundation for future work on development of novel approaches for remediating maladaptive choice behavior.

\section{References}

Ambroggi F, Ishikawa A, Fields HL, Nicola SM (2008) Basolateral amygdala neurons facilitate reward-seeking behavior by exciting nucleus accumbens neurons. Neuron 59:648-661. CrossRef Medline

Ambroggi F, Ghazizadeh A, Nicola SM, Fields HL (2011) Roles of nucleus accumbens core and shell in incentive-cue responding and behavioral inhibition. J Neurosci 31:6820-6830. CrossRef Medline

Bari A, Mar AC, Theobald DE, Elands SA, Oganya KC, Eagle DM, Robbins TW (2011) Prefrontal and monoaminergic contributions to stop-signal task performance in rats. J Neurosci 31:9254-9263. CrossRef Medline

Bechara A, Damasio H (2002) Decision-making and addiction: I. Impaired activation of somatic states in substance dependent individuals when pondering decisions with negative future consequences. Neuropsychologia 40:1675-1689. CrossRef Medline

Belova MA, Paton JJ, Morrison SE, Salzman CD (2007) Expectation modu- lates neural responses to pleasant and aversive stimuli in primate amygdala. Neuron 55:970-984. CrossRef Medline

Belova MA, Paton JJ, Salzman CD (2008) Moment-to-moment tracking of state value in the amygdala. J Neurosci 28:10023-10030. CrossRef Medline

Beyeler A, Namburi P, Glober GF, Simonnet C, Calhoon GG, Conyers GF, Luck R, Wildes CP, Tye KM (2016) Divergent routing of positive and negative information from the amygdala during memory retrieval. Neuron 90:348-361. CrossRef Medline

Bonnett KA, Peterson KE (1974) A modification of the jump-flinch technique for measuring pain sensitivity in rats. Pharmacol Biochem Behav 3:47-55. CrossRef Medline

Cahill L, Haier RJ, White NS, Fallon J, Kilpatrick L, Lawrence C, Potkin SG, Alkire MT (2001) Sex-related difference in amygdala activity during emotionally influenced memory storage. Neurobiol Learn Mem 75:1-9. CrossRef Medline

Cahill L, Uncapher M, Kilpatrick L, Alkire MT, Turner J (2004) Sex-related hemispheric lateralization of amygdala function in emotionally influenced memory: an FMRI investigation. Learn Mem 11:261-266. CrossRef Medline

Crowley TJ, Dalwani MS, Mikulich-Gilbertson SK, Du YP, Lejuez CW, Raymond KM, Banich MT (2010) Risky decisions and their consequences: neural processing by boys with Antisocial Substance Disorder. PLoS One 5:e12835. CrossRef Medline

Dalton GL, Phillips AG, Floresco SB (2014) Preferential involvement by nucleus accumbens shell in mediating probabilistic learning and reversal shifts. J Neurosci 34:4618-4626. CrossRef Medline

Dekkers TJ, Popma A, Agelink van Rentergem JA, Bexkens A, Huizenga HM (2016) Risky decision making in Attention-Deficit/Hyperactivity Disorder: a meta-regression analysis. Clin Psychol Rev 45:1-16. CrossRef Medline

De Martino B, Kumaran D, Seymour B, Dolan RJ (2006) Frames, biases, and rational decision-making in the human brain. Science 313:684-687. CrossRef Medline

Di Ciano P, Cardinal RN, Cowell RA, Little SJ, Everitt BJ (2001) Differential involvement of NMDA, AMPA/kainate, and dopamine receptors in the nucleus accumbens core in the acquisition and performance of pavlovian approach behavior. J Neurosci 21:9471-9477. Medline

Di Ciano P, Robbins TW, Everitt BJ (2008) Differential effects of nucleus accumbens core, shell, or dorsal striatal inactivations on the persistence, reacquisition, or reinstatement of responding for a drug-paired conditioned reinforcer. Neuropsychopharmacology 33:1413-1425. CrossRef Medline

Fernando AB, Urcelay GP, Mar AC, Dickinson TA, Robbins TW (2014) The role of the nucleus accumbens shell in the mediation of the reinforcing properties of a safety signal in free-operant avoidance: dopamine-dependent inhibitory effects of D-amphetamine. Neuropsychopharmacology 39:1420 1430. CrossRef Medline

Floresco SB, McLaughlin RJ, Haluk DM (2008) Opposing roles for the nucleus accumbens core and shell in cue-induced reinstatement of foodseeking behavior. Neuroscience 154:877-884. CrossRef Medline

Georgiou P, Zanos P, Bhat S, Tracy JK, Merchenthaler IJ, McCarthy MM, Gould TD (2017) Dopamine and stress system modulation of sex differences in decision making. Neuropsychopharmacology. Advance online publication. Retrieved Jul. 25, 2017. doi: 10.1038/npp.2017.161. CrossRef Medline

Ghods-Sharifi S, St Onge JR, Floresco SB (2009) Fundamental contribution by the basolateral amygdala to different forms of decision making. J Neurosci 29:5251-5259. CrossRef Medline

Giesbrecht CJ, Mackay JP, Silveira HB, Urban JH, Colmers WF (2010) Countervailing modulation of Ih by neuropeptide $\mathrm{Y}$ and corticotrophinreleasing factor in basolateral amygdala as a possible mechanism for their effects on stress-related behaviors. J Neurosci 30:16970-16982. CrossRef Medline

Goldstein JM, Seidman LJ, Horton NJ, Makris N, Kennedy DN, Caviness VS Jr, Faraone SV, Tsuang MT (2001) Normal sexual dimorphism of the adult human brain assessed by in vivo magnetic resonance imaging. Cereb Cortex 11:490-497. CrossRef Medline

Gonzalez R, Schuster RM, Mermelstein RM, Diviak KR (2015) The role of decision-making in cannabis-related problems among young adults. Drug Alcohol Depend 154:214-221. CrossRef Medline

Gore F, Schwartz EC, Brangers BC, Aladi S, Stujenske JM, Likhtik E, Russo MJ, Gordon JA, Salzman CD, Axel R (2015) Neural representations of 
unconditioned stimuli in basolateral amygdala mediate innate and learned responses. Cell 162:134-145. CrossRef Medline

Gourley SL, Olevska A, Zimmermann KS, Ressler KJ, Dileone RJ, Taylor JR (2013) The orbitofrontal cortex regulates outcome-based decision-making via the lateral striatum. Eur J Neurosci 38:2382-2388. CrossRef Medline

Gowin JL, Mackey S, Paulus MP (2013) Altered risk-related processing in substance users: imbalance of pain and gain. Drug Alcohol Depend 132: 13-21. CrossRef Medline

Helmstetter FJ, Bellgowan PS (1994) Effects of muscimol applied to the basolateral amygdala on acquisition and expression of contextual fear conditioning in rats. Behav Neurosci 108:1005-1009. CrossRef Medline

Hernádi I, Grabenhorst F, Schultz W (2015) Planning activity for internally generated reward goals in monkey amygdala neurons. Nat Neurosci 18: 461-469. CrossRef Medline

Hosking JG, Cocker PJ, Winstanley CA (2014) Dissociable contributions of anterior cingulate cortex and basolateral amygdala on a rodent cost/benefit decision-making task of cognitive effort. Neuropsychopharmacology 39:1558-1567. CrossRef Medline

Janak PH, Tye KM (2015) From circuits to behaviour in the amygdala. Nature 517:284-292. CrossRef Medline

Kaye WH, Wierenga CE, Bailer UF, Simmons AN, Bischoff-Grethe A (2013) Nothing tastes as good as skinny feels: the neurobiology of anorexia nervosa. Trends Neurosci 36:110-120. CrossRef Medline

Kilpatrick LA, Zald DH, Pardo JV, Cahill LF (2006) Sex-related differences in amygdala functional connectivity during resting conditions. Neuroimage 30:452-461. CrossRef Medline

Maren S, Aharonov G, Fanselow MS (1996) Retrograde abolition of conditional fear after excitotoxic lesions in the basolateral amygdala of rats: absence of a temporal gradient. Behav Neurosci 110:718-726. CrossRef Medline

Mitchell MR, Weiss VG, Beas BS, Morgan D, Bizon JL, Setlow B (2014) Adolescent risk taking, cocaine self-administration, and striatal dopamine signaling. Neuropsychopharmacology 39:955-962. CrossRef Medline

Najavits LM, Meyer T, Johnson KM, Korn D (2011) Pathological gambling and posttraumatic stress disorder: a study of the co-morbidity versus each alone. J Gambl Stud 27:663-683. CrossRef Medline

Namburi P, Beyeler A, Yorozu S, Calhoon GG, Halbert SA, Wichmann R, Holden SS, Mertens KL, Anahtar M, Felix-Ortiz AC, Wickersham IR, Gray JM, Tye KM (2015) A circuit mechanism for differentiating positive and negative associations. Nature 520:675-678. CrossRef Medline

Orsini CA, Trotta RT, Bizon JL, Setlow B (2015a) Dissociable roles for the basolateral amygdala and orbitofrontal cortex in decision-making under risk of punishment. J Neurosci 35:1368-1379. CrossRef Medline

Orsini CA, Moorman DE, Young JW, Setlow B, Floresco SB (2015b) Neural mechanisms regulating different forms of risk-related decision-making: Insights from animal models. Neurosci Biobehav Rev 58:147-167. CrossRef Medline

Orsini CA, Willis ML, Gilbert RJ, Bizon JL, Setlow B (2016) Sex differences in a rat model of risky decision making. Behav Neurosci 130:50-61. CrossRef Medline

Park K, Lee S, Kang SJ, Choi S, Shin KS (2007) Hyperpolarization-activated currents control the excitability of principal neurons in the basolateral amygdala. Biochem Biophys Res Commun 361:718-724. CrossRef Medline

Park K, Yi JH, Kim H, Choi K, Kang SJ, Shin KS (2011) HCN channel activity-dependent modulation of inhibitory synaptic transmission in the rat basolateral amygdala. Biochem Biophys Res Commun 404:952-957. CrossRef Medline

Paton JJ, Belova MA, Morrison SE, Salzman CD (2006) The primate amygdala represents the positive and negative value of visual stimuli during learning. Nature 439:865-870. CrossRef Medline

Piantadosi PT, Yeates DC, Wilkins M, Floresco SB (2017) Contributions of basolateral amygdala and nucleus accumbens subregions to mediating motivational conflict during punished reward-seeking. Neurobiol Learn Mem 140:92-105. CrossRef Medline

Ramirez F, Moscarello JM, LeDoux JE, Sears RM (2015) Active avoidance requires a serial basal amygdala to nucleus accumbens shell circuit. J Neurosci 35:3470-3477. CrossRef Medline

Rangel A, Camerer C, Montague PR (2008) A framework for studying the neurobiology of value-based decision making. Nat Rev Neurosci 9:545556. CrossRef Medline

Roiser JP, de Martino B, Tan GC, Kumaran D, Seymour B, Wood NW, Dolan
RJ (2009) A genetically mediated bias in decision making driven by failure of amygdala control. J Neurosci 29:5985-5991. CrossRef Medline

Saddoris MP, Gallagher M, Schoenbaum G (2005) Rapid associative encoding in basolateral amygdala depends on connections with orbitofrontal cortex. Neuron 46:321-331. CrossRef Medline

Sangha S, Chadick JZ, Janak PH (2013) Safety encoding in the basal amygdala. J Neurosci 33:3744-3751. CrossRef Medline

Saunders BT, Robinson TE (2012) The role of dopamine in the accumbens core in the expression of Pavlovian-conditioned responses. Eur J Neurosci 36:2521-2532. CrossRef Medline

Schneider S, Peters J, Bromberg U, Brassen S, Miedl SF, Banaschewski T, Barker GJ, Conrod P, Flor H, Garavan H, Heinz A, Ittermann B, Lathrop M, Loth E, Mann K, Martinont JL, Nees F, Paus T, Rietschel M, Robbins TW, et al. (2012) Risk taking and the adolescent reward system: a potential common link to substance abuse. J Psychiatry 169:39-46. CrossRef Medline

Schoenbaum G, Chiba AA, Gallagher M (1998) Orbitofrontal cortex and basolateral amygdala encode expected outcomes during learning. Nat Neurosci 1:155-159. CrossRef Medline

Schoenbaum G, Chiba AA, Gallagher M (1999) Neural encoding in orbitofrontal cortex and basolateral amygdala during olfactory discrimination learning. J Neurosci 19:1876-1884. Medline

Schoenbaum G, Setlow B, Saddoris MP, Gallagher M (2003) Encoding predicted outcome and acquired value in orbitofrontal cortex during cue sampling depends upon input from basolateral amygdala. Neuron 39: 855-867. CrossRef Medline

Shabel SJ, Janak PH (2009) Substantial similarity in amygdala neuronal activity during conditioned appetitive and aversive emotional arousal. Proc Natl Acad Sci U S A 106:15031-15036. CrossRef Medline

Simon NW, Gilbert RJ, Mayse JD, Bizon JL, Setlow B (2009) Balancing risk and reward: a rat model of risky decision making. Neuropsychopharmacology 34:2208-2217. CrossRef Medline

St Onge JR, Abhari H, Floresco SB (2011) Dissociable contributions by prefrontal D1 and D2 receptors to risk-based decision making. J Neurosci 31:8625-8633. CrossRef Medline

St Onge JR, Stopper CM, Zahm DS, Floresco SB (2012) Separate prefrontalsubcortical circuits mediate different components of risk-based decision making. J Neurosci 32:2886-2899. CrossRef Medline

Stopper CM, Floresco SB (2011) Contributions of the nucleus accumbens and its subregions to different aspects of risk-based decision making. Cogn Affect Behav Neurosci 11:97-112. CrossRef Medline

Stuber GD, Sparta DR, Stamatakis AM, van Leeuwen WA, Hardjoprajitno JE, Cho S, Tye KM, Kempadoo KA, Zhang F, Deisseroth K, Bonci A (2011) Excitatory transmission from the amygdala to nucleus accumbens facilitates reward seeking. Nature 475:377-380. CrossRef Medline

Tremblay M, Cocker PJ, Hosking JG, Zeeb FD, Rogers RD, Winstanley CA (2014) Dissociable effects of basolateral amygdala lesions on decision making biases in rats when loss or gain is emphasized. Cogn Affect Behav Neurosci 14:1184-1195. CrossRef Medline

Wassum KM, Izquierdo A (2015) The basolateral amygdala in reward learning and addiction. Neurosci Biobehav Rev 57:271-283. CrossRef Medline

Winstanley CA, Floresco SB (2016) Deciphering decision making: variation in animal models of effort- and uncertainty-based choice reveals distinct neural circuitries underlying core cognitive processes. J Neurosci 36: 12069-12079. CrossRef Medline

Winstanley CA, Theobald DE, Cardinal RN, Robbins TW (2004) Contrasting roles of basolateral amygdala and orbitofrontal cortex in impulsive choice. J Neurosci 24:4718-4722. CrossRef Medline

Womble MD, Moises HC (1993) Hyperpolarization-activated currents in neurons of the rat basolateral amygdala. J Neurophysiol 70:2056-2065. Medline

Zeeb FD, Winstanley CA (2011) Lesions of the basolateral amygdala and orbitofrontal cortex differentially affect acquisition and performance of a rodent gambling task. J Neurosci 31:2197-2204. CrossRef Medline

Zeeb FD, Winstanley CA (2013) Functional disconnection of the orbitofrontal cortex and basolateral amygdala impairs acquisition of a rat gambling task and disrupts animals' ability to alter decision-making behavior after reinforcer devaluation. J Neurosci 33:6434-6443. CrossRef Medline

Zhang W, Schneider DM, Belova MA, Morrison SE, Paton JJ, Salzman CD (2013) Functional circuits and anatomical distribution of response properties in the primate amygdala. J Neurosci 33:722-733. CrossRef Medline 